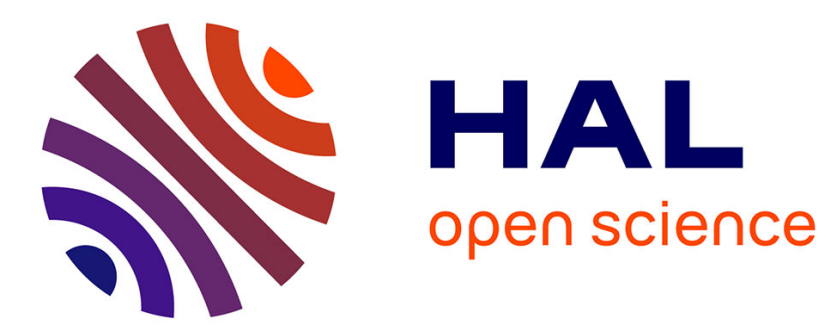

\title{
A Smart Grid Voltage Sag Detector using an EEMD-Based Approach
}

Yassine Amirat, Mohamed Benbouzid

\section{To cite this version:}

Yassine Amirat, Mohamed Benbouzid. A Smart Grid Voltage Sag Detector using an EEMD-Based Approach. 2013 IEEE IEMDC, May 2013, Chicago, United States. pp.1300-1304. hal-00874044

\section{HAL Id: hal-00874044 \\ https://hal.science/hal-00874044}

Submitted on 17 Oct 2013

HAL is a multi-disciplinary open access archive for the deposit and dissemination of scientific research documents, whether they are published or not. The documents may come from teaching and research institutions in France or abroad, or from public or private research centers.
L'archive ouverte pluridisciplinaire HAL, est destinée au dépôt et à la diffusion de documents scientifiques de niveau recherche, publiés ou non, émanant des établissements d'enseignement et de recherche français ou étrangers, des laboratoires publics ou privés. 


\title{
A Smart Grid Voltage Sag Detector using an EEMD-Based Approach
}

\author{
Yassine Amirat, Member, IEEE and Mohamed Benbouzid, Senior Member, IEEE
}

\begin{abstract}
Smart grids have become a focal point in renewable energy source researches. Sustainability and viability of distributed grids are highly dependent on the reduction of the operational and maintenance costs. The most efficient way of reducing these costs would be to continuously monitor the condition of these systems. This allows for early detection of the power quality degeneration, and facilitating a proactive response, prevent a fault ride-through the renewable energy conversion system, minimizing downtime, and maximizing productivity.

This paper provides then the assessment of an advanced signal processing technique (demodulation tool) using the instantaneous power for voltage sags detection in smart grids.
\end{abstract}

Index Terms-Smart grid, voltage sag detection, power quality (PQ), ensemble empirical mode decomposition (EEMD).

\section{INTRODUCTION}

Renewable energy conversion systems are the fastestgrowing sources of new electric generation in the world and it is expected to remain so for sometimes, and those sources are becoming a reliable competitor of classical power generation systems, which are facing to constantly changing operating parameters, such as fuel cost, multiple fuel tradeoffs and maintaining older systems becomes more costly; and actually a volte-face is made against nuclear power station that can cause human disaster. These systems offer an alternative and emerging solution by deploying hybrid power plant offshore or onshore, where there are substantial renewable resources, leading to a best electricity generating opportunities. With the deployment of distributed renewable power generation; the electricity networks are undergoing wholesale changes both from generation and the user sides. Unlike the classic power plants which are far from the user, the actual tendency is to move generation system nearby the distribution level and this can be achieved by using a set of micro grids and energy islands based on renewable sources, connected to the main grid as illustrated in Fig. 1 [1-2].

Y. Amirat is with ISEN, EA 4325 LBMS, 20, Rue Cuirassé Bretagne, 29200 Brest, France (e-mail: Yassine.Amirat@isen.fr).

M.E.H Benbouzid is with the University of Brest, EA 4325 LBMS, Rue de Kergoat, CS 93837, 29238 Brest, France (e-mail: Mohamed.Benbouzid@univ-brest.fr).
Hence, this topology allows micro grids parallel operation to main grid or isolated as an energy island. This philosophy requires flexible micro grids that will be able to meet the power demand needs and have islanding fast capabilities when a fault occurs such as voltage sags or power outage; this is known as a smart grid. So, key considerations when deploying smart grids are their availability, reliability, and profitability; in order to fulfill power demand according to PQ standards. In this context, voltage sags automated detection is indexed as an essential requirement for a condition monitoring system in order to meet PQ standards [3-4]. So, a deep knowledge about all the phenomena involved during the occurrence of voltage sag constitutes an essential background for the development of any condition monitoring systems. Regarding a fault as a particular input acting on a power system (grid), a detection system must be able to detect its occurrence, as well as to isolate it from all other inputs such as disturbances and controls affecting the behavior of the system.

It is therefore obvious that monitoring is a key issue that needs to be addressed to make a grid more intelligent. This requires much more sophisticated computer-oriented monitoring than in a classical grid [1]. In this context, signal processing is certain to play a significant role in dealing with the complexity and uncertainty associated with a smart grid [5]. This paper provides then the assessment of an advanced signal processing technique; namely the ensemble empirical mode decomposition (EEMD). EEMD is mainly a signal processing technique to extract distinctive features; namely intrinsic mode functions (IMFs). Feature selection requires a series of calculations based on statistics such as maxima, minima, singular value, standard deviation, and mean [6]. The instantaneous power will be used as the electrical quantity for voltage sag detection.

\section{VolTAGE SAGS}

Voltage sags are defined as a deviation of the RMS supply voltage from a reference value with typical dip depths ranging from 0.9 to $0.5 \mathrm{pu}$ of a $1 \mathrm{pu}$ nominal [7]; lasting from few milliseconds to few cycles, unlike under voltage or over voltage that occur for long periods. Voltage sags are therefore a transient voltage amplitude deviation. They are caused by abrupt increases in loads such as phase to phase or phase to ground short circuits, they are also caused by abrupt increases in source impedance, typically caused by a loose connection.

The most usual voltage sags signatures are depicted in Fig. 2 [4]. During a voltage sag three-phase system balanced conditions are no longer valid leading to possible disastrous consequences on the user end-loads and on the smart grid itself. 


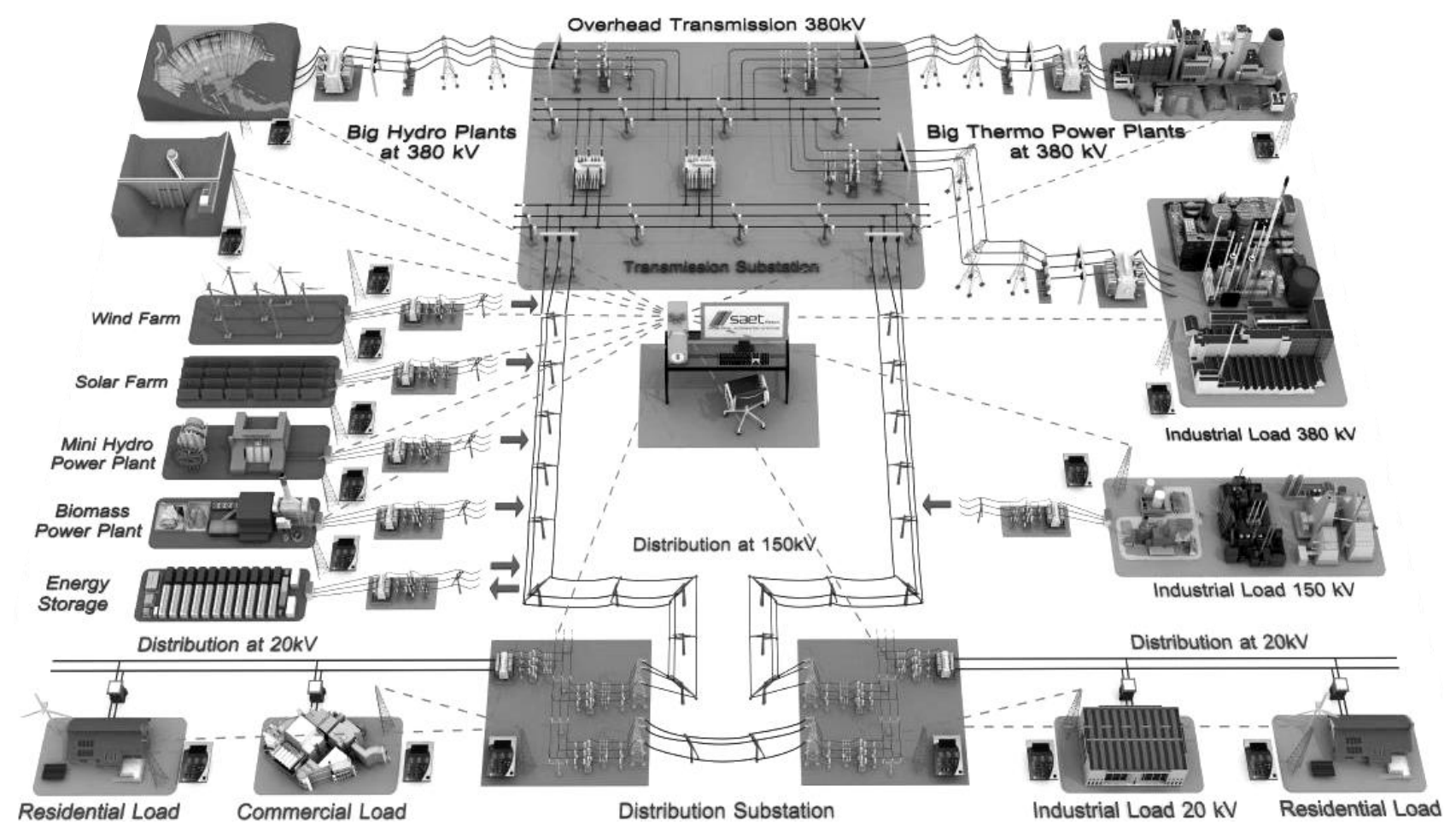

Fig. 1. A smart grid topology [@ SAET].
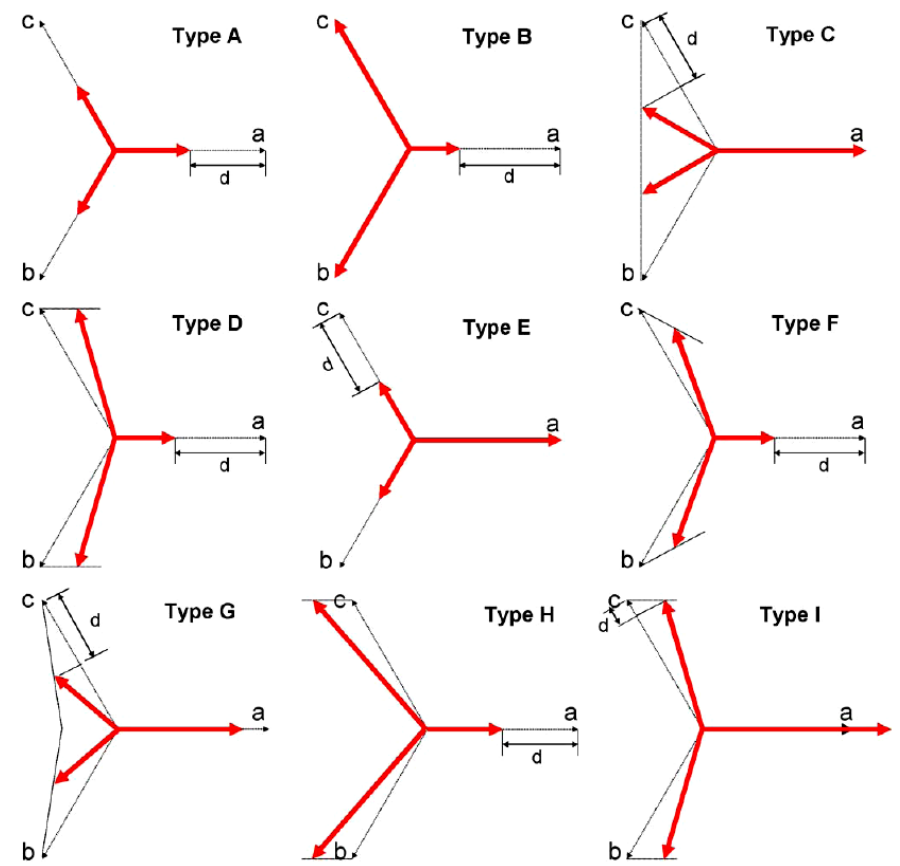

Fig. 2. Voltage sag main signatures [4].

Voltage sag characterization concerns events quantification through a limited number of parameters. These parameters depend on the field of study. However, main characterization methods use two parameters to determine the severity of a voltage sag: magnitude (or "remaining voltage") and duration [3]. In the context of a smart grid, it is therefore important to know whether voltage sag exists and afterward estimate its duration.

\section{EEMD-BASED Voltage SAg Detection TeChNIQUE}

For voltage sag detection, there is a wide range of technology and methods derived from contemporary power systems where condition monitoring systems use pre-installed sensors that are managed together in different architectures and coupled with algorithms to allow a smart grid efficient monitoring [8-11].

Well-established methods are those based on electrical quantity signatures analysis (current, voltage, power, etc.). Indeed, those quantities are easily accessible or evaluated during operation. Electrical quantities analysis usually involves the use of reference frame transformations such as Park's vector [10] or three-phase system symmetrical components or space vector [4], and other techniques based upon them. These techniques however assume that voltage and current quantities are pure sine waves, while in real-world the electrical quantities are polluted by harmonics produced by power electronic devices in both sides of the smart grid, and transient spikes due to grid apparatus maneuvers. It is therefore obvious the Fast Fourier Transform (FFT), and other techniques based upon, are no longer valid even they has been used in some cases [7]. Advanced signal processing techniques are therefore required to deal with the complexity and uncertainty associated with a smart grid. In [12], a TeagerKaiser energy operator has been proposed for power system oscillations detection and analysis. However, this operator is highly affected by noises.

It seems that one of the emerging methods for transient signal processing is the empirical modal decomposition (EMD) [6]. The EMD method has focused considerable attention and has been indexed recently for power system fault 
detection and analysis [12-13]. Indeed and contrary to wellknown decomposition techniques, EMD is intuitive and direct, with the basic functions based on and derived from the data.

The EMD is an adaptive time-frequency data analysis method for nonlinear and non-stationary signals. It is used to decompose the multi-component signal into a series of IMFs based on the signal time-scale local characteristics. However, one major drawback of the EMD is the mode mixing. This phenomenon means that the detail related to one scale can appear in two different intrinsic modes. To overcome this drawback, the EEMD was introduced [15]. The EEMD is described as a new noise-added method, which mitigate automatically the EMD mode-mixing. It is described in the flowchart given in Fig. 3.

\section{RESULTS AND DISCUSSIONS}

In order to assess the ability of the proposed approach to detect voltage sag, real data were used. Those data were fed by the DOE/EPRI National Database Repository of Power System Events [15].

Figure 4 clearly shows that voltage sag in a three-phase system produces a voltage dip in each phase with a sharp variation in the current amplitude and a phase-shift.

Since voltage sag effect arises in voltages and currents, it seems more relevant to use the three-phase instantaneous power given by $p(t)=\sum_{k=a, b, c} v_{k}(t) i_{k}(t)$

to investigate voltage sag occurrence.

For illustration, Fig. 5 clearly shows that the instantaneous power is a key variable to monitor a smart grid regarding voltage sag. Indeed, it contains the above-mentioned ( $\$$ III) relevant parameters (fault appearance time and duration).

After decomposing the instantaneous power according to the EEMD algorithm, several IMFs were obtained. The most energized is the $4^{\text {th }}$ one. Figure 6 depicts then the instantaneous power and its $4^{\text {th }}$ IMF. In particular, it is clearly shown that this IMF is very sensitive to the voltage sag occurrence and its duration. This is confirmed when intrinsic modes decomposition is carried-out during a phase voltage cycle that corresponds to $16.66 \mathrm{msec}$ or 128 samples of the instantaneous power. Indeed, this is illustrated by Figs 7 and 8 that show respectively the instantaneous power amplitude and the $4^{\text {th }}$ IMF for each processing interval.

The shortest path to the $4^{\text {th }}$ IMF amplitude information is the statistic variance $\sigma^{2}$ given by

$\sigma_{i m f_{4}}^{2}=\frac{1}{N} \sum_{n=0}^{N-1}\left[i m f_{4}(n)-\mu_{i m f_{4}}\right]^{2}$

After the EEMD processing, the $4^{\text {th }}$ IMF variance is computed in each interval and collected in Table 1.
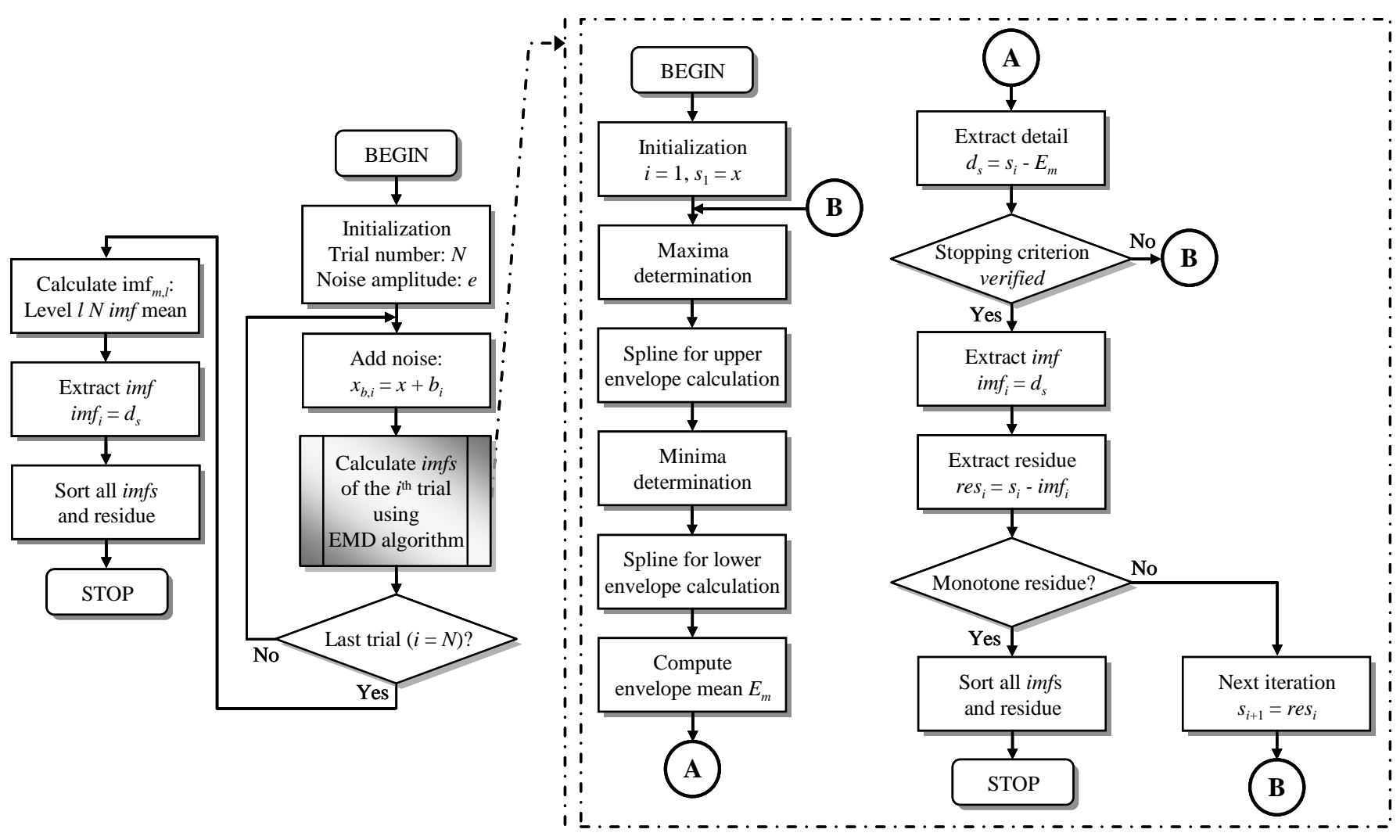

Fig. 3. EEMD algorithm flowchart. 


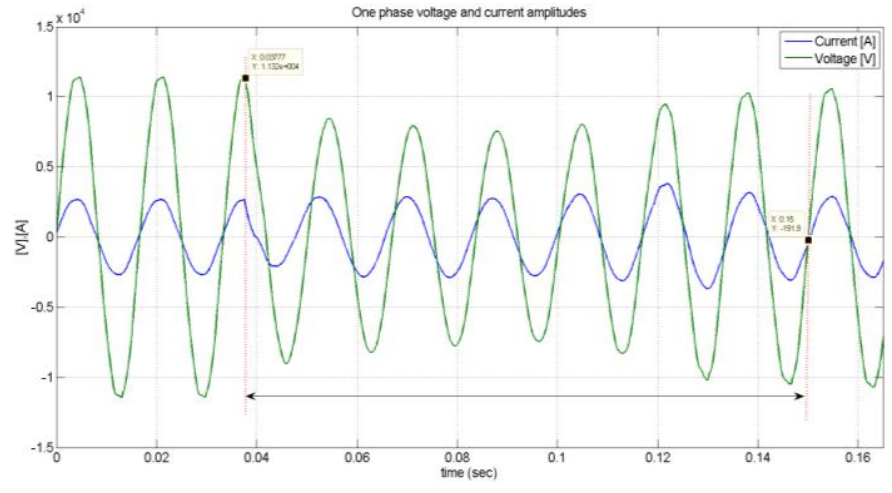

(a) Phase $a$.

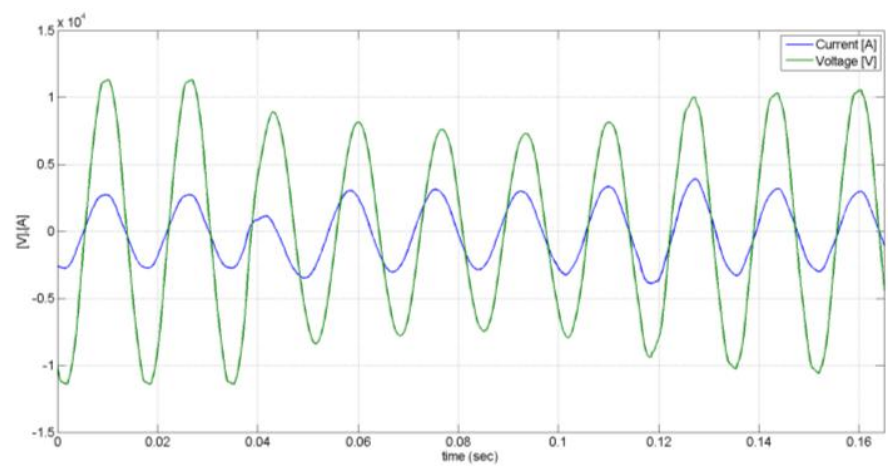

(a) Phase $b$.

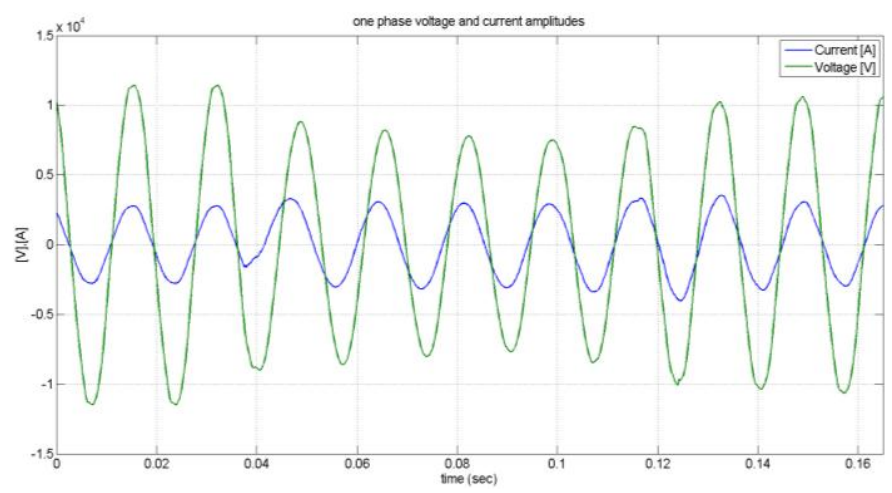

(a) Phase $c$.

Fig. 4.Voltage and current before, during and after voltage sag.
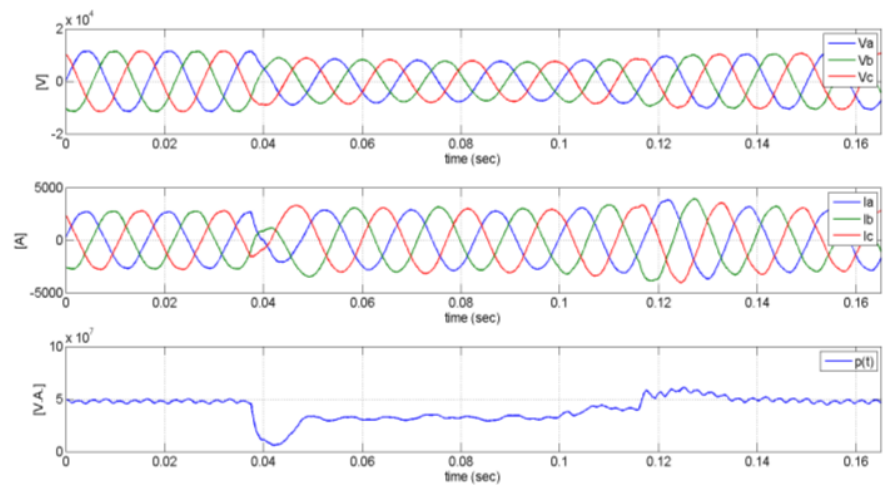

Fig. 5. Phase voltages, currents, and the total instantaneous power before, during and after voltage sag.
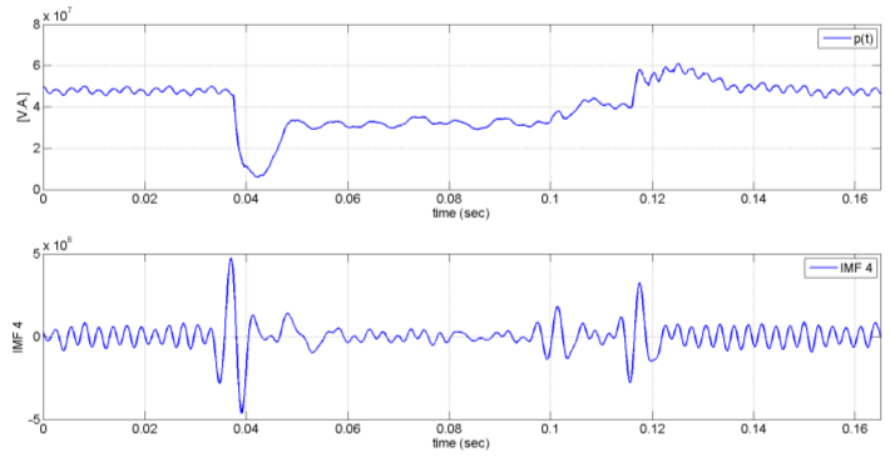

Fig. 6. Instantaneous power and its $4^{\text {th }} \mathrm{IMF}$ before, during and after voltage sag.

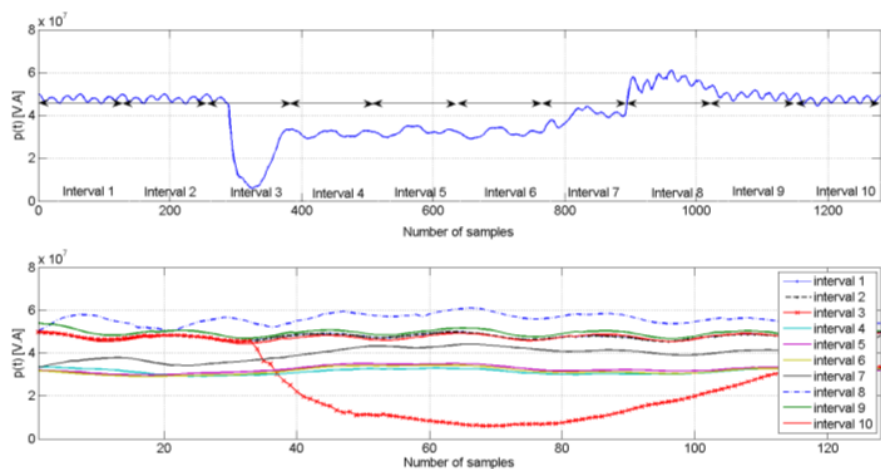

Fig. 7. Instantaneous power during each processing interval.

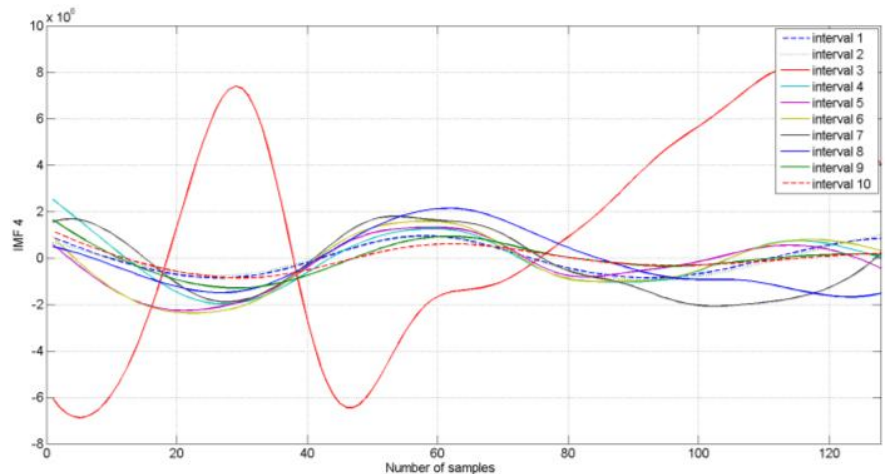

Fig. 8. Instantaneous power $4^{\text {th }}$ IMF for each processing interval.

Table $1.4^{\text {th }}$ IMF variance.

\begin{tabular}{|c|c|c|c|c|c|}
\hline Interval & 1 & 2 & 3 & 4 & 5 \\
\hline$\sigma^{2}$ & $3.80 \%$ & $3.80 \%$ & $234.43 \%$ & $11.01 \%$ & $11.08 \%$ \\
\hline \hline Interval & 6 & 7 & 8 & 9 & 10 \\
\hline$\sigma^{2}$ & $14.25 \%$ & $18.36 \%$ & $14.37 \%$ & $4.36 \%$ & $2.05 \%$ \\
\hline
\end{tabular}

According to the electrical quantities waveforms, for the $1^{\text {st }}$ and $2^{\text {nd }}$ voltage cycles, normal operation is confirmed by the variance reduced and constant value $\left(\sigma^{2}=3.8 \%\right)$ in the $1^{\text {st }}$ and 
$2^{\text {nd }}$ intervals. At a voltage sag occurrence ( $3^{\text {rd }}$ cycle), the variance obviously increases to $234.48 \%$ and remains between $11 \%$ and $14 \%$ during the voltage sag. Afterward, it decreases to a small value at the $9^{\text {th }}$ and $10^{\text {th }}$ intervals. It is therefore clearly demonstrated that the $4^{\text {th }}$ IMF can be used as the prime variable for monitoring voltage sags in terms of detection and duration estimation using a grid voltage cycle as time-base.

\section{CONCLUSION}

This paper dealt with voltage sag detection in a smart grid using the instantaneous power quantity. This quantity was first decomposed into intrinsic mode functions through the EEMD. It was then found that the $4^{\text {th }}$ one is the most energized when voltage sag occurs. The $4^{\text {th }}$ IMF mode is then analyzed using a statistic criterion based on the variance. The achieved results clearly show that it can be used an effective indicator for voltage sag detection and smart grid monitoring.

\section{REFERENCES}

[1] M.G. Simões and al., "A comparison of smart grid technologies and progresses in Europe and the US," IEEE Trans. Industry Applications, vol. 48, n²4, pp. 1154-1162, July/August 2012.

[2] M. Glinkowski, J. Hou and G. Rackliffe, "Advances in wind energy technologies in the context of smart grid," Proc. IEEE, vol. 99, n ${ }^{\circ}$, pp. 1083-1097, June 2011.

[3] E. Gómez-Lázaro, J.A. Fuentes, A. Molina-García, M. Cañas-Carretón, "Characterization and visualization of voltage dips in wind power installations," IEEE Trans. Power Delivery, vol. 24, n²4, pp. 2071-2078, October 2009.
[4] V. Ignatova, P. Grangon and S. Bacha, "Space vector method for voltage dips and swells analysis," IEEE Trans. Power Delivery, vol. 24, nº 4 , pp. 2054-2061, October 2009

[5] Y. Xia, S.C. Douglas and D.P. Mandic, "Adaptative frequency estimation in smart grid applications," IEEE Signal Processing Magazine, vol. 29, n5, pp. 44-54, September 2012.

[6] Y. Lei, J. Lin, Z. He and M.J. Zuo, "A review on empirical mode decomposition in fault diagnosis of rotating machinery," Mechanical Systems and Signal Processing, vol. 35, n 1-2, pp. 108-126, February 2013.

[7] C. Fitzer, M. Barns and P. Green, "Voltage sag detection technique for a dynamic voltage restorer," IEEE Trans. Industry Applications, vol. 40, $\mathrm{n}^{\circ} 1$, pp. 203-212, January/February 2004.

[8] A.N. Milioudis, G.T. Andreou and D.P. Labridis, "Enhanced protection scheme for smart grids using power line communications techniquesPart I: Detection of high impedance fault occurrence," IEEE Trans. Smart Grid, vol. 3, nº, pp. 1621-1630, December 2012.

[9] A.N. Milioudis, G.T. Andreou and D.P. Labridis, "Enhanced protection scheme for smart grids using power line communications techniquesPart II: Location of high impedance fault position," IEEE Trans. Smart Grid, vol. 3, n, pp. 1631-1640, December 2012.

[10] G.A. Orcajo, J.M. Cano, M.G. Melero, M.F. Cabanas, C.H. Rojas, J.F. Pedrayes and J.G. Noriella, "Diagnosis of electrical distribution network short circuits based on voltage Park's vector," IEEE Trans. Power Delivery, vol. 27, nº, pp. 1964-1972, October 2012.

[11] K.D. McBee and M.G. Simões, "Utilizing a smart grid monitoring system to improve voltage quality of customers," IEEE Trans. Smart Grid, vol. 3, n², pp. 738-743, June 2012.

[12] I. Kamwa, A. K. Pradhan, and G. Joos, "Robust Detection and analysis of power system oscillation using Teager-Kaiser energy Operator," IEEE Trans. Power Systems, vol. 26, n¹, pp.323-333, February 2011.

[13] O. Ozgonenel, T. Yalcin, I. Guney and U. Kurt, "A new classification for power quality events in distribution systems," Electric Power Systems Research, vol. 95, pp. 192-199, February 2013.

[14] Y. Amirat, V. Choqueuse and M.E.H. Benbouzid, "Wind turbine bearing failure detection using generator stator current homopolar component ensemble empirical mode decomposition," in Proceedings of the 2012 IEEE IECON, Montreal (Canada), pp. 3937-3942, October 2012.

[15] http://www.expertmonitoring.com/doelibrary/index.html 